\title{
NUMERICAL ANALYSIS OF HEAT TRANSFER IN REFRIGERANT FLOW THROUGH A CONDENSER TUBE
}

\author{
Chandrasekar.R ${ }^{1}$, Raja. $T^{2}$, Santhosh.J $\mathbf{J}^{3}$, Arunkumar.S ${ }^{4}$ \\ ${ }^{1}$ Assistant Professor, Department of Mechanical Engineering, VMKV Engineering college, Tamilnadu, India \\ ${ }^{2}$ Associate Professor, Department of Automobile Engineering, VMKV Engineering College, Tamilnadu, India \\ ${ }^{3}$ Assistant Professor, Department of Mechanical Engineering, VMKV Engineering college, Tamilnadu, India \\ ${ }^{4}$ Assistant Professor, Department of Mechanical Engineering, VMKV Engineering college, Tamilnadu, India
}

\begin{abstract}
In this thesis, heat transfer analysis of refrigerant flow in a condenser tube has been done. The main objective of this thesis is to find the length of the condenser tube for a pre-defined refrigerant inlet state such that the refrigerant at the tube outlet is saturated liquid or sub cooled liquid. The inlet refrigerant condition is saturated vapor. The problem involves refrigerant flowing inside a straight, horizontal copper tube over which air is in cross flow. Inlet condition of the both fluids and condenser tube detail except its length are specified. Here, changing pressure at discrete points along the tube is calculated by using two-phase frictional pressure drop and momentum equation mode. The heat transfer calculation has done by using condensation heat transfer correlations and simple heat transfer equations. The inside heat transfer coefficient calculated by using two phase heat transfer coefficient correlation. The unknown length of condenser tube has discrete many numbers of small elements. Each and every element has a calculations based on the pressure drop as well as heat transfer based on those correlation and every element calculated properties of refrigerant values has to check its states. At end of the iteration, a last element has reached saturated liquid condition of refrigerant and stops the entire calculation. So the length of condenser tube has been calculated by number of iteration and number of nodes with its distance. Predicted values were compared using another condensation heat transfer correlations. A computer-code using Turbo C has been developed for performing the entire calculation.
\end{abstract}

Keywords: Heat transfer, Refrigeration, Multi phase flow, condenser flow, Tube length

\section{INTRODUCTION}

In internal condensation, the vapor and liquid flow simultaneously flows inside the channel or pipe. The resulting two phase flow is more complicated physically than single phase flow. Also the usual inertia, viscous and pressure forces present in single phase flow and two phase flows. These are affected by interfacial tension forces, the wetting characteristics of the liquid on the tube wall and the exchange of momentum between the liquid and vapor phases in the flow. Because of these effects, the analysis of two phase flow patterns varies for different geometries of channels or tubes and their orientations. Condensation inside horizontal tubes is governed by a combination of gravity forces and interfacial shear stresses, the relative contribution of which change with geometry and fluid flow conditions. Generalized analytical treatment of the vapor - liquid flow is extremely difficult due to this.

An important and still growing part of the engineering research community has been devoted in the last few decades to scaling down devices, while keeping or even increasing their functionality.

\section{PROBLEM DESCRIPTION}

The problem involves refrigerant flowing through a straight, horizontal copper tube over which air is in cross flow. Inlet conditions of both the fluids and condenser tube detail except its length are specified. The main objective is to find the length of the condenser tube for a pre defined inlet refrigerant state such that the refrigerant at the tube outlet is saturated liquid or sub cooled liquid.

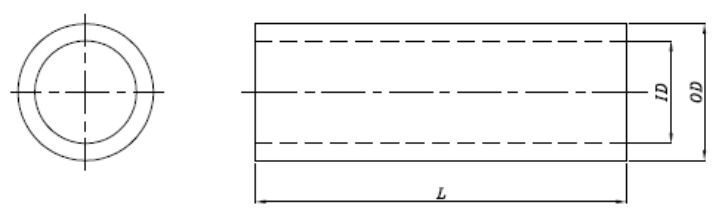

Fig -1: Geometry of condenser tube

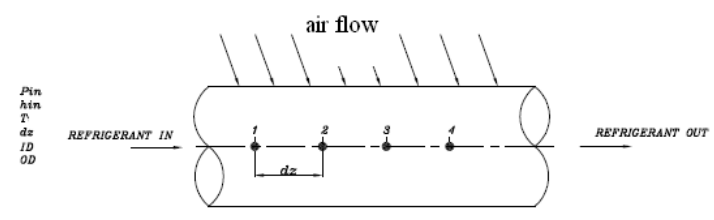

Fig -2: Problem Visualization

\section{SOLUTION APPROACH}

We require two properties to fix the state of the refrigerant i.e., pressure and enthalpy. In this analysis pressure and enthalpy can be found at discrete points along the length of the tube. For calculating enthalpy one ordinary differential equation is required. This can be obtained by balancing energy, which flows through an elementary strip. 


$$
\begin{gathered}
m_{f} h_{z}+d q=m_{f} h_{z+d z} \\
h_{z}-h_{z+d z}=\frac{2 \pi\left(T_{r e f}-T_{\text {air }}\right) d z}{m_{f}\left(\frac{1}{\alpha_{i} r_{i}}+\frac{\ln \left(\frac{r_{o}}{r_{i}}\right)}{k}+\frac{1}{\alpha_{o} r_{o}}\right)}
\end{gathered}
$$

In equation, $\alpha_{i}$ and $\alpha_{o}$ are inside and outside heat transfer coefficients respectively. The inside heat transfer coefficients can be found from condensation heat transfer correlations by Cavallini-Zecchin and outside heat transfer coefficient is calculated from the correlations of flow over bodies. Then enthalpy at next node can be found by using above equation.

\subsection{Pressure Drop Calculations}

For calculating the pressure we require another differential equation, which gives the pressure drop between two nodes. Pressure drop includes both frictional pressure drop as well as acceleration pressure drop. Frictional pressure drop can be obtained from Lockhard and Martinelli model. Acceleration pressure drop can be obtained from momentum equation along axial direction.

$$
\begin{aligned}
& {\left[\frac{d p}{d z}\right]_{l i q}=\frac{2 f_{l i q} G^{2}(1-X)^{2}}{D \rho_{l i q}}} \\
& {\left[\frac{d p}{d z}\right]_{\text {vap }}=\frac{2 f_{\text {vap }} G^{2} X^{2}}{D \rho_{\text {vap }}}}
\end{aligned}
$$

The flow decelerates along the condensation path resulting in an increase in pressure. If we use appropriately averaged velocities for each phase, and a constant tube-diameter, we can obtain the acceleration pressure drop using a simplified, one-dimensional momentum equation.In two-phase flow, the momentum changes of both the A force balance on a liquid and the vapor must be taken into account.

$$
\Delta P_{\text {mom }}=-G^{2}\left\{\left[\frac{X^{2}}{\rho_{\text {vap }} \theta}+\frac{(1-X)^{2}}{\rho_{\text {liq }}(1-\theta)}\right]_{\text {out }}-\left[\frac{X^{2}}{\rho_{\text {vap }} \theta}+\frac{(1-X)^{2}}{\rho_{\text {liq }}(1-\theta)}\right]_{\text {in }}\right\}
$$

By using pressure and enthalpy, state of the refrigerant can be fixed at next node. Length of the tube can be found by marching from one node to another until the state of the refrigerant is saturated liquid or sub cooled liquid.

\subsection{Input Parameters to be specified}

- Refrigerant inlet pressure

- Refrigerant inlet temperature

- Name of the refrigerant
- Mass flow rate of the refrigerant

- Air velocity

- Air temperature

- Inner diameter of the tube

- Outer diameter of the tube

- Space between two nodes

\subsection{Over-all Heat Transfer Coefficient Calculation} The average heat transfer coefficient is obtained by integrating the local heat transfer correlations over the quality range of the corresponding condensing length. In addition, correlations may be specific or general. Specific correlations apply to particular fluids or flow regimes, while general correlations can be used for several types of fluids. The various heat transfer coefficient correlations for condensation considered for the simulation. Those are listed below

\subsubsection{Cavallini-Zecchin correlation}

Where,

$$
\alpha_{T P}=0.05 \operatorname{Re}_{e q} \operatorname{Pr}_{\text {liq }}\left(\frac{k_{\text {liq }}}{D}\right)
$$

$$
\operatorname{Re}_{e q}=\operatorname{Re}_{l i q}+\operatorname{Re}_{v a p}\left[\frac{\mu_{v a p}}{\mu_{l i q}}\right]\left[\frac{\rho_{l i q}}{\rho_{v a p}}\right]
$$

Where,

$$
\begin{aligned}
& \mathrm{Re}_{\text {iqq }}=\left(\frac{G D}{\mu_{\text {iqq }}}\right)\left(1-X_{\text {ref }}\right) \\
& \mathrm{Re}_{\text {vap }}=\left(\frac{G D}{\mu_{v a p}}\right)\left(X_{r e f}\right) \\
& \operatorname{Pr}_{l i q}=\left(\frac{\mu_{l i q} C p_{l i q}}{k_{l i q}}\right)
\end{aligned}
$$

\subsubsection{Shah Correlation}

$$
\frac{\alpha_{T P}}{\alpha_{1}}=1+\frac{3.8}{Z^{0.95}}
$$

Where,

$$
\begin{aligned}
& \alpha_{1}=\alpha\left(1-X_{r e f}\right) \\
& Z=\left(\frac{1}{X_{r e f}}-1\right)^{0.8} \mathrm{P}_{\text {red }}^{0.4} \quad \mathrm{P}_{\text {red }}=\frac{\mathrm{P}_{\text {sat }}}{\mathrm{P}_{\text {crit }}}
\end{aligned}
$$

\subsection{Air Side Heat Transfer Coefficients}

Air side heat transfer coefficients were calculated from the experimental data using a Wilson plot, a technique developed to determine the individual heat transfer coefficients in a heat exchanger. Alternatively, tabulated data may be used. When using data from the literature, it is important to choose a condenser design that closely resembles the one being simulated. 


$$
\operatorname{Re}_{\mathrm{D}}=\frac{u_{\propto} d_{o d}}{\gamma}
$$

$$
\mathrm{Nu}_{\mathrm{D}}=C \operatorname{Re}_{D}{ }^{m} \operatorname{Pr}^{0.333}
$$

Table1. Value of $\mathrm{C}$ and $\mathrm{m}$

\begin{tabular}{|l|l|l|}
\hline $\operatorname{Re}_{\mathrm{D}}$ & $\mathrm{C}$ & $\mathrm{m}$ \\
\hline $0.4-4$ & 0.989 & 0.330 \\
\hline $4-40$ & 0.911 & 0.385 \\
\hline $40-4000$ & 0.683 & 0.466 \\
\hline $4000-40000$ & 0.193 & 0.618 \\
\hline $40000-400000$ & 0.0266 & 0.805 \\
\hline
\end{tabular}

\section{RESULTS AND DISCUSSIONS}

The following data are input to the computer code.

- Refrigerant inlet pressure $-18.121 \mathrm{bar}$

- Refrigerant inlet Enthalpy - $417.54 \mathrm{KJ} / \mathrm{Kg}$

- Name of the refrigerant - R-22

- Mass flow rate of the refrigerant- 30,45 and $60 \mathrm{Kg} / \mathrm{s}$

- Air velocity $-4 \mathrm{~m} / \mathrm{s}$

- Air temperature $-25^{\circ} \mathrm{C}$

- Inner diameter of the tube - .5,10,15,20 and $25 \mathrm{~mm}$

- $\quad$ Outer diameter of the tube - 7,12,17,22 and $27 \mathrm{~mm}$

- Space between two nodes - $5 \mathrm{~mm}$

As the inside diameter decreases, the required length of heat exchanger increases. The flow regime becomes wavy over a substantial portion of the heat exchanger. In the wavy flow regime, increase in the diameter decreases the thermal resistance, which results in a slightly shorter heat exchanger. This same thing occurs at both flow rates, as exhibited by the similar shape of the curves. The low mass flow rate curves are exhibits substantially less sensitivity to diameter because the refrigerant side resistance is much smaller when compared to the air side resistance. It is shown in below figure-3.

The two phase frictional flow multiplier increases along the length due to increase of velocity of both phases. Therefore, frictional pressure drop increases. When the mass flow rate increases, two phase velocity increases. As the velocity increases shear stress between the fluid and the tube wall increases. So pressure drop increases. It is shown in below figure-4.

Enthalpy decreases along length of the tube linearly, which is got from an ordinary linear differential equation. Enthalpy difference is inversely proportional to the mass flow rate of the refrigerant. Total resistance to the heat transfer is varying linearly along the length of tube. If the mass flow rate increases enthalpy difference decreases for same length of the tube. It is shown in below figure-5.

Saturated temperature decreases along length of the tube. It behaves similar to pressure. As the flow progresses saturated pressure decreases thereby temperature decreases. For the larger mass flow rate the slope of the curve is larger, hence the temperature difference is more for larger mass flow rate. It is shown in below figure-6.

Dryness fraction decreases linearly along length of the tube. It behaves similar to enthalpy. The slope of the curve with lower mass flow rate is lowest. So for a given length, change in dryness fraction is large for largest mass flow rate. Length of the tube for lowest mass flow rate of refrigerant is small. It is shown in figure-7.

Inside heat transfer coefficient decreases along the length of the tube. At high quality regions i.e., at entrance of the tube, there is more significance of mass flow rate on heat transfer coefficient and in that region forced convective condensation is predominant. As the dryness fraction decreases film condensation occurs. If the mass flow rate of the refrigerant increases, heat supplied to the tube is taken away faster, which eventually increases heat transfer. In other words higher velocity yields higher heat transfer coefficients. It is shown in figure-8.

Outside heat transfer coefficient increases along the length of the tube as outside wall temperature decreases. It is having less significance compared to inside heat transfer coefficient. Slope of the curve with larger mass flow rate is small. It is shown in figure-9.

Inside heat transfer coefficient along the length of the tube varies linearly in Cavallini-Zecchin correlation. But shah correlation shows that there is a large variation in the value at the beginning as well as the end of the condensation. It is shown in figure 10 .

Length of condenser tube for different mass flow rates and different correlations are compared and finally checked for energy conservation. It is shown in below table.

Table2. Comparison of energy balance and Length of

\begin{tabular}{|c|c|c|c|c|c|}
\hline $\begin{array}{l}\mathrm{S} . \\
\mathrm{N} \\
\mathrm{O}\end{array}$ & $\begin{array}{l}\text { Mass } \\
\text { flow } \\
\text { rate(k } \\
\mathrm{g} / \mathrm{hr})\end{array}$ & $\begin{array}{l}\text { correlatio } \\
\mathrm{ns}\end{array}$ & $\begin{array}{l}\text { Heat } \\
\text { gained } \\
\text { by } \\
\text { air(W) }\end{array}$ & $\begin{array}{l}\text { Heat } \\
\text { lost by } \\
\text { refriger } \\
\text { ant(W) }\end{array}$ & $\begin{array}{l}\text { Length } \\
\text { (m) }\end{array}$ \\
\hline \multirow{3}{*}{1} & \multirow{3}{*}{60} & $\begin{array}{l}\text { Cavallini- } \\
\text { Zecchin }\end{array}$ & 2655.05 & 2655.04 & 59.81 \\
\hline & & Shah & 2655.32 & 2655.25 & 60.17 \\
\hline & & $\begin{array}{l}\text { Traviss et } \\
\text { al }\end{array}$ & 2655.23 & 2655.20 & 60.36 \\
\hline \multirow{3}{*}{2} & \multirow{3}{*}{45} & $\begin{array}{l}\text { Cavallini- } \\
\text { Zecchin }\end{array}$ & 1985.25 & 1985.25 & 44.725 \\
\hline & & Shah & 1985.17 & 1985.17 & 45.05 \\
\hline & & $\begin{array}{l}\text { Traviss et } \\
\text { al }\end{array}$ & 1985.34 & 1985.24 & 45.23 \\
\hline \multirow{3}{*}{3} & \multirow{3}{*}{30} & $\begin{array}{l}\text { Cavallini- } \\
\text { Zecchin }\end{array}$ & 1321.13 & 1321.13 & 30.56 \\
\hline & & Shah & 1321.06 & 1321.02 & 30.36 \\
\hline & & $\begin{array}{l}\text { Traviss et } \\
\text { al }\end{array}$ & 1321.14 & 1321.09 & 30.51 \\
\hline
\end{tabular}
condenser tube for different mass flow rates 


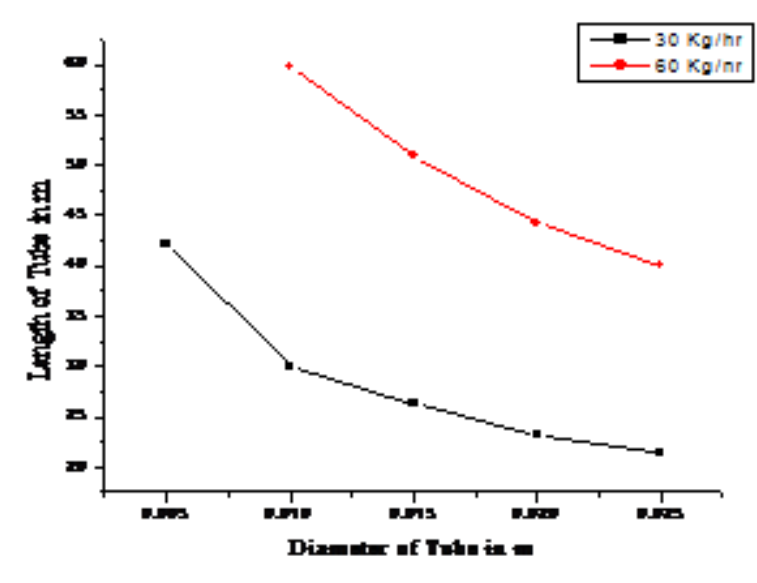

Fig -3: Variation of length of the tube along the different diameter of tube with different mass flow rates

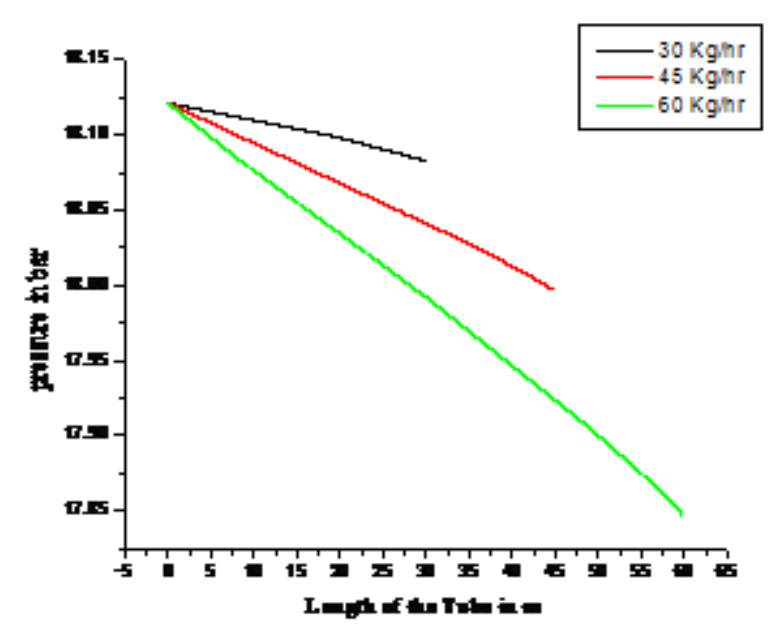

Fig -4: Variation of Pressure of R-22 along length of the condenser tube for different mass flow rates

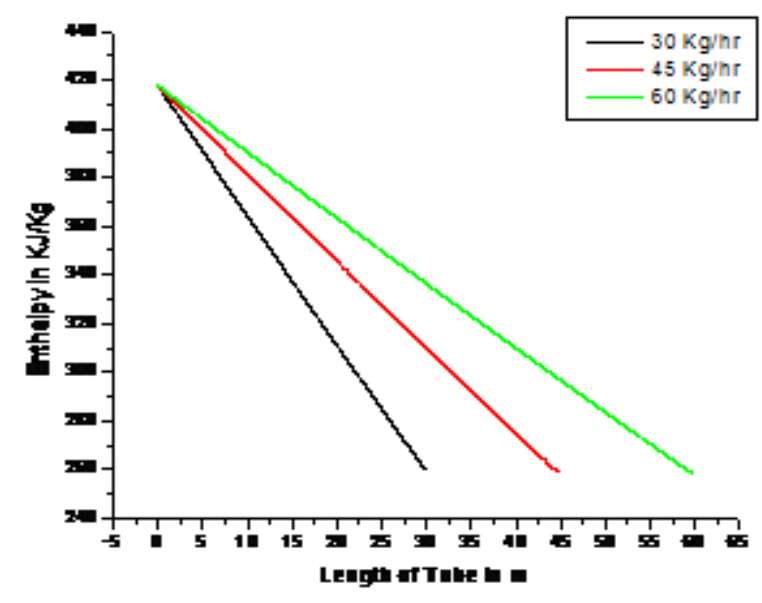

Fig -5: Variation of enthalpy of R-22 along length of the condenser tube for different mass flow rates

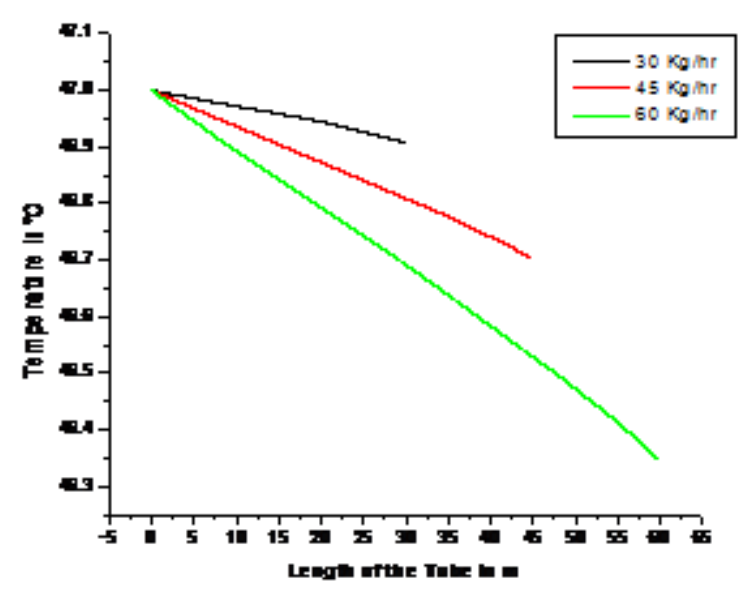

Fig -6: Variation of Temperature of R-22 along length of the condenser tube for different mass flow rates

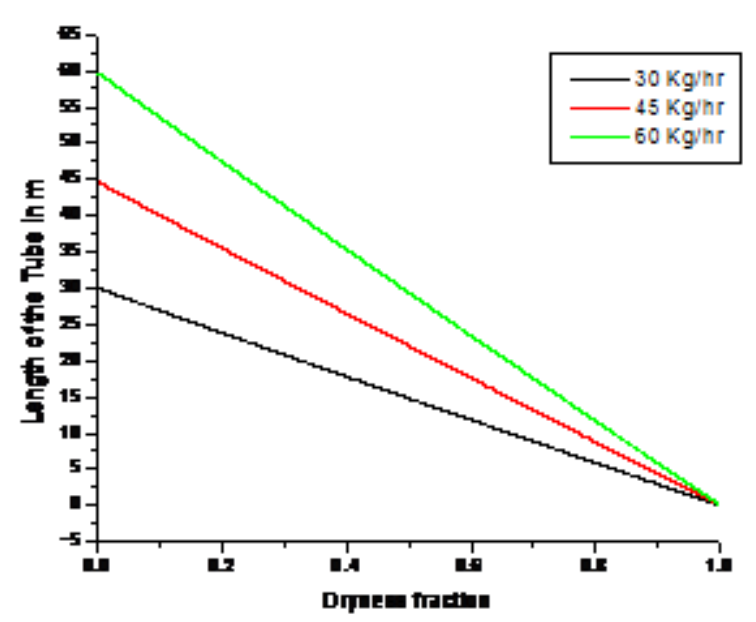

Fig -7: Variation of Dryness fraction of R-22 along length of the condenser tube for different mass flow rates

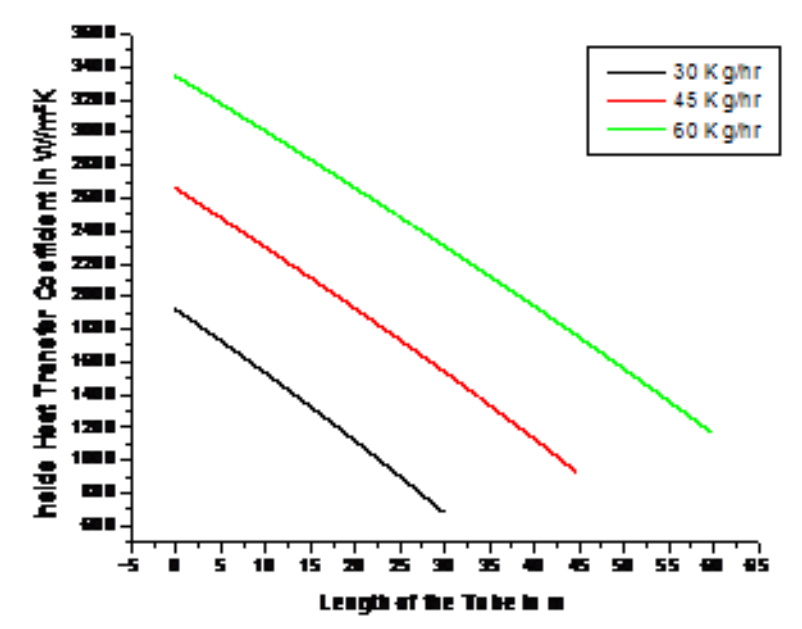

Fig -8: Variation of inside heat transfer coefficient of R-22 along length of the condenser tube for different mass flow rates 


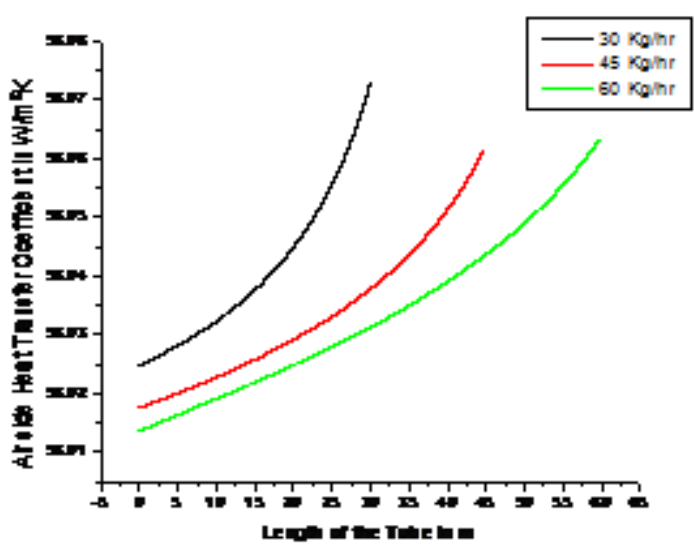

Fig -9: Variation of Air side heat transfer coefficient of R22 along length of the condenser tube for different mass flow rates

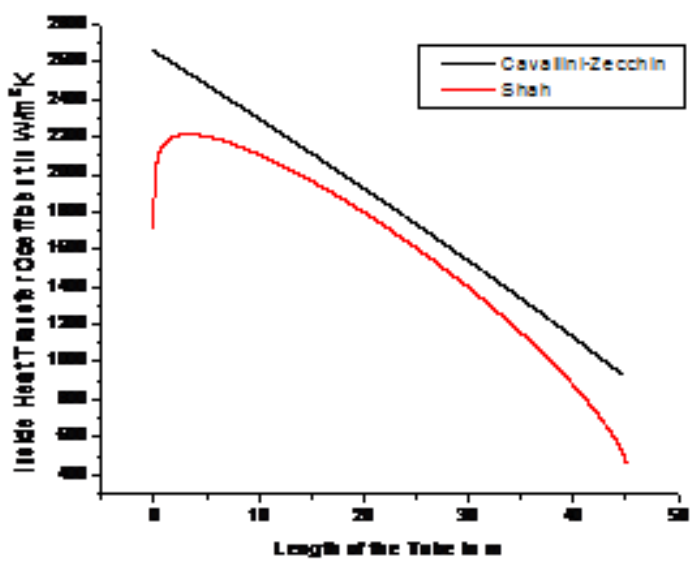

Fig -10: Variation of Inside heat transfer coefficient of R-22 along length of the condenser tube at $45 \mathrm{~kg} / \mathrm{hr}$ mass flow rate for different correlations

\section{CONCLUSIONS}

- $\quad$ Pressure decreases along length of the tube as frictional flow multiplier increases due to increase of velocity of both phases (liquid and vapor). If the mass flow rate increases, two-phase velocity increases and therefore pressure drop increases. So frictional pressure drop is large. At larger saturation pressures, ratio of densities of liquid and vapor of refrigerant is low. Observed frictional pressure drop was small at larger saturation pressures.

- Enthalpy decreases along length of the tube. The difference in enthalpy is inversely proportional to mass flow rate. If the mass flow rate is large, enthalpy decrement less. At larger saturation pressures the observed enthalpy difference was small due to lower overall temperature difference and overall resistance to flow was large.

- Inside heat transfer coefficient decreases along the length of the tube. This is due to increasing of heat flux along the tube. If the mass flow rate increases, increasing heat transfer was observed due to larger velocities. This is due to direct condensation of decelerating vapor and complete suppressing of condensation heat transfer.

- It was observed that if the mass flow rate increases, length of the tube was increasing due to larger pressure drop and less decrement in enthalpy.

The obtained results were satisfactory and energy was conserved for all refrigerant inlet states.

\section{REFERENCES}

[1] S. P. Wang and J. C. Chato, "Review of Recent Research on Boiling and Condensation Heat Transfer With Mixtures"- ACRC, University of Illinois.

[2] A. L. Souza, J. C. Chato, J. M. S. Jabardo, J. P. Wattelet, J. Panek, B. Christoffersen, and N. Rhines, "Pressure Drop During Two-Phase Flow Of Refrigerants In Horizontal Smooth Tube”-ACRC Technical Report 25, 1992.

[3] M. K. Dobson, J. C. Chato, D. K. Hinde, and S. P. Wang, "Experimental Evaluation of Internal Condensation of Refrigerants $R-134 a$ and R-12" ASHRAE Transactions, 1994.

[4] M.K. Dobson, J.C. Chato, S.P. Wang, D. Hinde, J. Gaibel, "Initial Condensation Comparison Of $R-22$ With R-134a And R-32/R-12s"- ACRC Technical Report 41, 1994.

[5] B. R. Christoffersen, J. C. Chato, J. P. Wattelet, and A. L. de Souza, "Heat Transfer and Flow Characteristics of $R-22, R-321 R-125$ and $R-134 a$ In Smooth and Micro-Fin Tubes"- ACRC Technical Report 47, 1993

[6] C.P.Arora, "Refrigeration and Air Conditioning".Tata McGraw-Hill, 2000.

[7] YunusA.Cengel, "Heat Transfer- A Practical Approach" - Tata McGraw-Hill, 2006.

[8] M.L. Mathur and F.S. Mehta, "Properties of Refrigerant and Psychrometric tables and charts in S.I.Unit"- Jain Brothers, 2002.

[9] C.P.Kothandaraman and S.Subramanyan, "Heat and Mass Transfer Data Book”-New Age International, 2007.

\section{BIOGRAPHIES}

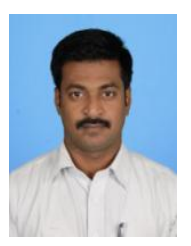

The author is working as assistant professor for past five years. He present many paper in various International Conference in the field of Heat transfer and fluid flow. He has much interest to research in the field Refrigeration and Air conditioning.

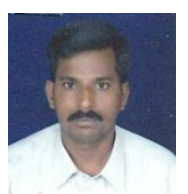

The author has good knowledge in automobile engineering. He has been head of automobile. $\mathrm{He}$ worked in various automobile industries and presented so many papers relevant to alternate fuel in various international conferences. 
The author working as assistant professor for past four years. He has good industrial experience in the field of designing and finite element analysis. He worked in defense related projects. He has much interest in the field of finite element analysis projects related toaero, thermal.

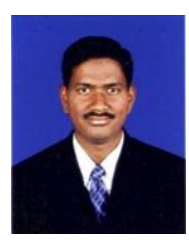

The author working as assistant professor for past six years. He has good industrial experience in the field of designing and manufacturing. He worked in defense related projects and manufacturing mechanical hardware. He has much interest in the manufacturing engineering. 